\title{
Playing in the field: participant observation and the investigation of intersubjective knowledge in jazz
}

\section{improvisation}

\author{
By Will Gibson (Institute of Education, London)
}

This paper investigates the use of intersubjective knowledge in the production of improvised jazz performance. I describe an approach to participant observation in which recordings of the researcher and research participants improvising musical performances together were used as 'texts' for framing discussions. A key methodological challenge in this investigation involved encouraging informants to provide sufficiently detailed verbal accounts of their commonsense knowledge. Through using these musical texts, the informants were able to provide a contextually rich commentary; in this way, our 'play' became a topic of conversation which shed light on the very practices I was interested in researching.

\section{Introduction}

The word 'play' can be used in diverse ways - to denote an activity distinct from 'work'; a means of relaxing; a way of learning; an 'informal' activity; a style of behaviour. In this discussion I use the concept of play to explore the ways in which participation within the activities being studied by researchers, whatever they may be, can yield rich data for creating detailed understandings of those practices. For me then, the term 'play' is being used to describe the participation in social practices with research participants. My concern however is not so much with the activity of producing these texts, but with the ways in which discussion of practice initiated through play can reveal in detail the ways in which intersubjective knowledge is used in specific contexts. In this paper, my empirical focus for exploring these issues is the ways in which jazz musicians use their knowledge about performance conventions in the course of producing improvisations.

In general terms, the notion of intersubjectivity involves a concern with examining the ways in which meanings are created by active intentional individuals, and are used, negotiated, contested and affirmed within a social world through interaction with other people. The ways in which we understand and build up a sense of 'meaning' is dependent on how we look at the world (Merleau-Ponty 1962), and the ways in which we 'look' or interpret the world and structure our experiences of it are situated within a social frame of reference. In this respect, 'social actors' participate in each others' perceptual fields, teaching each other about how and what they see, and arguing and debating over the relevance, appropriateness, or even correctness of these 'ways' (Crossley 1996:30). My interest here is in how recognisable 'community knowledge' is used by jazz musicians in the course of producing improvised performance. To examine this I look at what we might call, paraphrasing Goffman (1969), the 'musical interaction order'; i.e. the ways in which musicians 
make sense of and produce the sounds and gestures which form the core elements of musical improvisation. The key question that I seek to address here is: In what ways do musicians use their common-sense knowledge about these settings and the actions that comprise them to produce 'new' situationally appropriate improvised music?

This paper describes an approach to participant observation in which the participants and I recorded ourselves playing music together, and then recorded the discussions we had while playing back and listening to these recordings. Thus, by playing music with my research participants I was able to create a context for the type of contextually detailed conversation that I was interested in having. The requirement for using this approach came from the general failure of 'conventional' interviews to provide sufficiently detailed accounts. In the introductory section below I will describe the methodology in some detail, and provide an overview of the processes involved in jazz improvisation. I will then move to a discussion of some of the data that the approach elicited, and its relevance for my exploration of intersubjectivity.

\section{Methodological considerations}

I used participant observation as the main approach to my study, with interviews forming a significant part of the research process. Participant observation involves the use of a variety of methods of inquiry, including documentary analysis, interviews, and 'focus groups' (Hammersley and Atkinson 1983), to understand research settings from the point of view of those involved in them. Within my study, interviews played a particularly key part in the research because I wanted to understand the ways in which different 'roles' within the music and the use of specific kinds of instruments created perspectives of specialised knowledge and skill for approaching improvisation. As a guitar player I was to some extent an active member of the jazz community, but at that time I was only a neophyte member as I had only been playing for around four years. As such, I was yet to reach an acceptable level of skill to enable me to rely on my own knowledge as a good guide to the tacit 'rules' of participation. The challenge for me then was to somehow get musicians to articulate their conceptions of this knowledge to me. While my (partial) knowledge about what was involved in performance certainly helped create a basis for discussions, it was not sufficient to act as the main part of the analysis.

One of the central problems for me in undertaking this research was that it was difficult to get musicians to describe in detail the ways in which they used knowledge in the production of improvised performance. A part of the reason for this is that the assumptions that comprise the knowledge of how to improvise are tacitly held. A key challenge for researchers involved in examining social action of any kind involves finding ways to make the invisible visible; that is, to illicit articulations of what those in the research setting see as blindingly obvious. Garfinkel's (1967) infamous 'Breaching Experiments' achieved this by inviting his students to subvert the normal conditions of behaviour by, for example, 'behaving in your parents' house as you would in a guest house' (i.e. acting very formally within an informal environment). In such ways, the students were able to engender strong articulations of the 'sense of appropriateness' within which even mundane activities are typically orientated.

Within my research, the aim was to find ways to enable my interviewees to articulate what are, to them, 'ordinary' and taken for granted aspects of performance. While I 
did try to ask direct questions about the process of improvisation (such as, 'How do you start a solo?'; 'How do you develop musical ideas?'; 'How do you use your instrument to improvise?'), such approaches were rarely successful as they usually resulted in rather vague formulations. An alternative tactic involved inviting interviewees to provide examples of situations where normal playing order had broken down, and I then asked them to talk about why that happened and how they had responded to the problem. The idea was, as with Garfinkel's approach, to achieve expressions of their tacit assumptions. The success of this approach depended, as all interviews do (Benson and Hughes 1983:78), on the abilities of the interviewees to think of good examples of such events, and to provide detailed accounts of what had occurred. When working through the interview data I realised that, with some exceptions, there was generally a considerable lack of detail emerging; where detail was provided, the talk was sufficient to give a sense of the 'kinds of things' that happened in improvised musical conduct, but the accounts did not provide access to the detail of the events.

It is of course a well recognised limitation of research that is based on people's accounts, that the talk produced through the interaction between researcher and respondent(s) will give only partial insight into the activities to which such accounts pertain; to put the matter simply, producing talk about a particular activity relies on the abilities of interviewees to articulate complex issues in the confines of distinctive, and possibly unusual interactive settings, relying solely on what happens to come to mind at the time (Benson and Hughes 1983). Because of these considerations, my aim was to use the recordings of our performances together as a further referent which the interviewees could talk to, and therefore produce more nuanced, contextually situated reflections.

I do not wish to claim that the 'techniques' adopted in this paper-if 'techniques' is not too grand a term for a common-sense fix to a practical problem-are particularly innovative. Shieffelin (1990), for example, uses a similar approach in an investigation of language socialisation; having compiled transcribed sections of talk from interaction among Maluli children and parents, Schieffelin asked the mothers to help with the transcription process to aid the difficult task of discerning unclear words and identifying particular participants. Within the talk, Schieffelin made particular use of the comments of a Kaluli man who was able to draw out the significance of particular speech acts in a way that Schieffelin, as an outsider, could not-as Schieffelin put it, the method provided 'a means of extending and enriching the contextualizing ethnographic and linguistic information provided originally by the mothers' (1990:30). Other examples include Theureau and Geneviève's (2000) use of what they call 'self-confrontation interviews', in which traffic controllers in an urban traffic system were shown video-footage of their activities and asked to provide descriptions of what was happening.

In my study I conducted four performance-related interviews; for the purposes of this paper I will focus my discussion on just one of these. The interview to be discussed here is with a London-based session guitarist whom we will call John. ${ }^{1}$ I had met John some years previously when he was teaching at the music school at which I was a student. The interview procedure I had designed involved John and myself playing and recording a couple of songs, which we then played back and talked through,

\footnotetext{
${ }^{1}$ I have used a pseudonym here because the publication of this paper may go somewhat beyond the consent I sought for named inclusion in the original research.
} 
recording the talk as we went. In the discussion that follows I will explore some of the valuable data that this approach enabled me to collect, and explain its relevance to my interest in the use of intersubjective knowledge.

\section{An overview of the processes of jazz improvisation}

Providing a description of jazz improvisation is not easy because, apart from anything else, 'jazz' is a slippery term that is used to describe quite a diverse set of approaches to music performance (DeVeau 1991). My discussion will focus on the performance of 'modern jazz', which is distinct from both the 'traditional jazz' of the 1920s and 30s, and the 'free jazz' movement characterised by the abandonment of adherence to many (although not all) of the normalised performance conventions I will be discussing here. The term 'modern jazz' somewhat crudely groups together distinct phases within the jazz tradition, including 'swing', 'bebop', 'post-bop', 'hard-bop', and 'cool' (Townsend 2000). Notwithstanding their differences, these styles can be seen to have quite a number of similarities.

As with other forms of improvised conduct, jazz improvisation is achieved by participants orientating to a body of tacit knowledge about 'how to do improvisation' (Bailey, 1992); this tacit knowledge comprises not only the musicians' own skills and musical knowledge, but also awareness of the performance setting itself, the musical styles being orientated to, the level of experience of fellow musicians, and various other circumstantial factors that come into play in the creation of 'appropriate' music. Importantly, orientating to these conventions is not a matter of 'abiding by the rules' but of knowing the rules, and using them (Becker, 1982); this is a key theme in the discussion that follows.

Soling, or improvising, in modern jazz involves creating melodic lines with reference to the harmonic framework of a given tune. The tunes used as contexts for jazz improvisation comprise a melody and a chord structure. The jazz repertoire is made up of hundreds of 'standard tunes' that form a fundamental part of the repertoire or 'stock of knowledge' for jazz musicians. The harmonic framework of a tune is used by musicians as a map for improvisation. The tunes are comprised of musical 'bars' - typically eight, twelve, sixteen or thirty-two bars per song - one sequence of which is referred to as a 'chorus'. Having played the melody of the song as an ensemble unit, the musicians in the group take it in terms to improvise over the chord structure of the tune being played. When improvising over chord structures musicians do not play randomly, but orientate to an intersubjectively recognisable 'palette of possibilities'. It is therefore not the case that a musician can play 'anything at any time', as there are quite strict rules about which sounds are regarded as 'fitting' over particular chords.

Ordinary conversation forms a useful analogy for understanding the ways in which these expectations are used by musicians, an analogy which is frequently used in descriptions of jazz improvisation (Martin 1996). Within conversation, there are quite strict and publicly observable 'rules' about, for example, topics, turn-taking, vocabulary, and length of turns. Studies in conversation analysis have been concerned with explicating the ways in which conversation is produced through the mutual orientation to and working out of these often tacit structures (Heritage 1984). Jazz musicians create their music in relation to often taken-for-granted, background expectations of musical action, working out improvisatory schemas through the 
application of intersubjective knowledge and resources. My concern below is to look in detail at some of the ways in which this knowledge is oriented to in the creation of improvised music.

\section{Discussion}

I had heard John playing the song On A Clear Day a few days before at a gig, and so I suggested that we start by playing that. Before beginning, we briefly discussed how we would start the piece in order to arrange the key and tempo we would play in, and to sort out some ambiguities in the structure of the piece. Upon listening back afterwards to the introduction of the recording John noted, 'I was playing largely diatonic [within the harmony] on this tune because it's a happy sort of summery kind of feel. I didn't want to do anything strange on it. I feel about this tune like that, I like to start the opening section like that.' Figure 1 provides a transcription of John's improvised introduction.

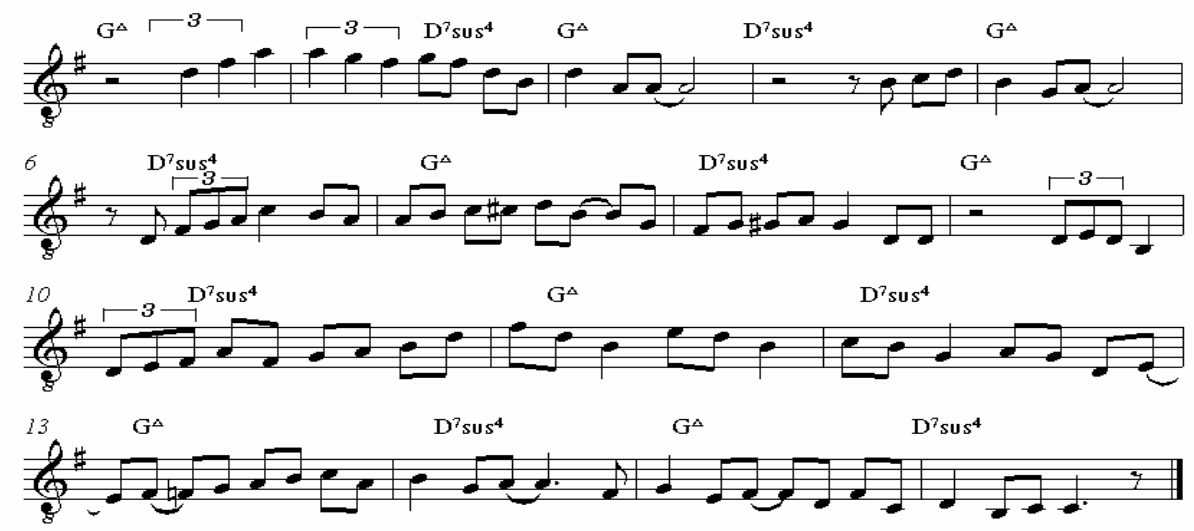

Figure 1

For John, the association of 'happy' and 'summery' was to some extent present in his orientation to improvisation, in that he deliberately selected note patterns that he saw as being appropriate to his reading of the 'emotional significance' of the tune. The issue of emotion and musical meaning is a treacherous field, and attempts to associate 'this kind of sound' with 'that kind of emotion' quickly run into problems as cultural practices and individual preferences vary widely (DeNora 2000, Martin 1995). It is nevertheless important to note that John's characterisation represents a claim about his interpretation of the music, and how that interpretation was used as a 'decision-making resource' to select certain notes rather than others. What is interesting about this example is the reference to 'not doing something strange'; in other words, adhering to the conventions of 'how you play over a G major chord', in order to create a sense of consonance and regularity.

Having talked briefly through the intro of the tune, we went on to discuss the way that John played the melody. Like the chord structure of the tune, the melody can be thought of as a loose set of directions rather than as a 'score' that needs to be rigorously adhered to. Thus, while musicians will generally know the melody well, 
they will typically not play it as written, but provide certain 'jazz like' embellishments. For example, within our recording John played the following line:

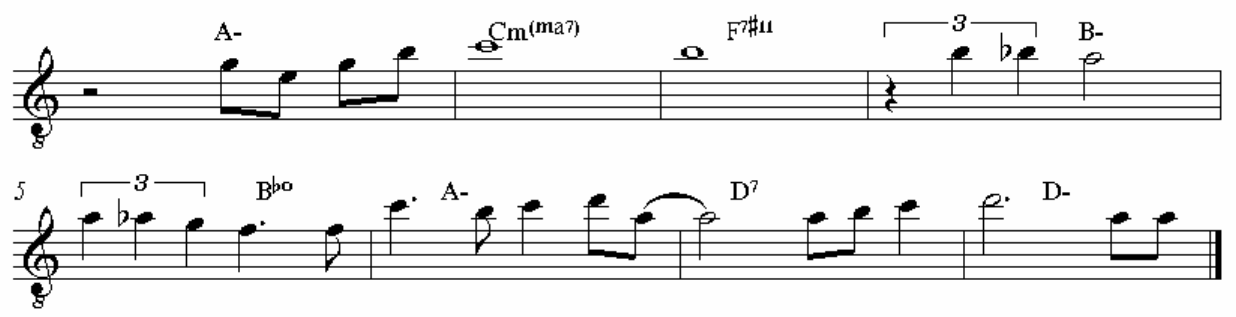

Figure 2

When he heard this back on the recording John noted, 'With the chromatic thing, and stuff like that, I like to make the most of it because it is in the melody; just before it goes chromatic I play a chromatic lead in...you know it's gonna be chromatic next so you go da, da da, da, da da [singing a chromatic line similar to bars four and five of Figure 2]'. John's description captures well the ways in which 'improvisation' while playing melody involves using its basic characteristics (tonalities, melodies, rhythmic patterns) as 'themes' to be played with. All members of the jazz community know these basic features (although they don't necessarily know them equally well), and, as such, changes of the melody in this way are quite easily detectable. For John, knowing what is coming next and anticipating it is a clear part of the improvisation of melody.

In what follows I will explore further three aspects of the performance that John's reflexive listening helped to identify: improvisation in relation to accompaniment; personal stylistic preferences; and the process of editing.

\section{Improvisation in relation to accompaniment}

In the second chorus of our performance of On A Clear Day, i.e. after we had played the melody, John played the following:

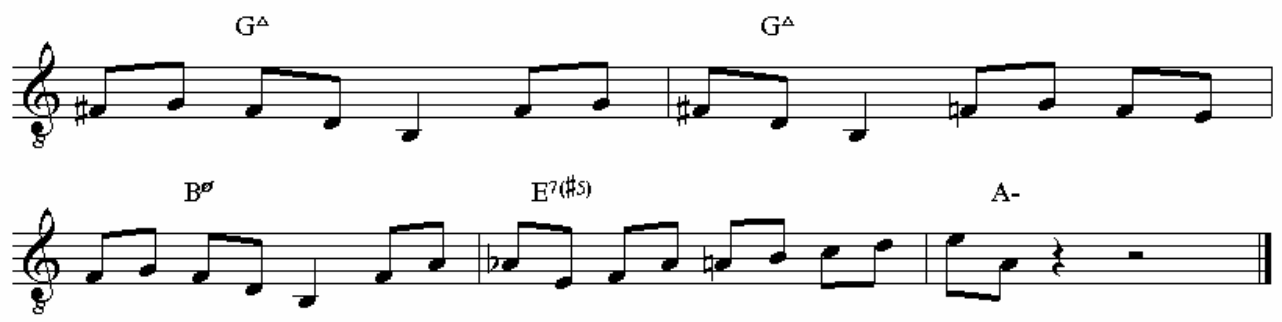

Figure 3 
When he heard this section played back John stopped the tape and excitedly explained what had happened:

you know that the major seventh chord [first two bars of the example], well, I was basically playing a B minor seventh over the G major seventh, so I was thinking of $B$ minor seventh instead of $G$ major seventh because I knew that you were gonna change to a B half diminished afterwards. Some people play straight B minor seventh but I heard you playing that [B half diminished] before and I knew that you went to the half diminished chord there, so I was gonna set that up and do it with you and then resolve.

This explanation involved using a technical musical vocabulary which I will try to convey in a more accessible way. This section of the musical 'script' comprises a movement from a $\mathrm{G}$ major seventh chord (bars one and two above) to a $\mathrm{B}$ minor chord (bar three). Musicians do not always play the chords of these song structures exactly as written, and frequently make certain non-arbitrary changes (i.e. alterations which accord with certain normal ways of doing things). John's comment shows that he had heard one of the alterations I had made in the first chorus of the tune, and anticipated that I would probably do the same thing again. John then decided to use his expectations of what I was going to do as a feature of his own improvisations by creating a melody which 'spelt out' the change that I was making, rather than the change that the original tune makes. In other words, John had used my playing as a means of selecting a specific sound from his 'palette of possibilities', to help develop a melodic idea that fit with what I was doing.

We see clearly in this example that the context of accompaniment was actively oriented to by John in the creation of an improvised melody. Far from being merely a background feature of the performance, the accompaniment was used as a strategy to improvisation. In constructing an improvised strategy, John listened to me, identified what I was doing, and created something that fitted 'appropriately', i.e. which could be seen by community members as 'consistent with' my chord playing. In terms of intersubjectivity then, the unfolding 'musical interaction order' and the knowledge used to make sense of it were used by John as a resource for guiding himself through the performance.

\section{Personal stylistic preferences}

While talking about the tape John noted that he preferred using intervallic type playing (by moving between non-adjacent scale tones) rather than a more lineal approach (i.e. building melodic lines that largely use adjacent notes). This talk stemmed from John hearing a part of the tape on which he had been using a bit of this lineal type of playing. John noted that,

I don't want to say too much in that scale wise playing. I like it, but for me it's nice to move things around a bit. I play non-chromatically a lot of the time because I prefer that kind of melody that moves around rather than just going da, da, da, da, da [sings upwards chromatic line].

John then demonstrated on his guitar two contrasting rhythmic approaches to the same harmonic situations (Figures 4 and 5), the former of which was more consistent with his preferred stylistic approaches. 

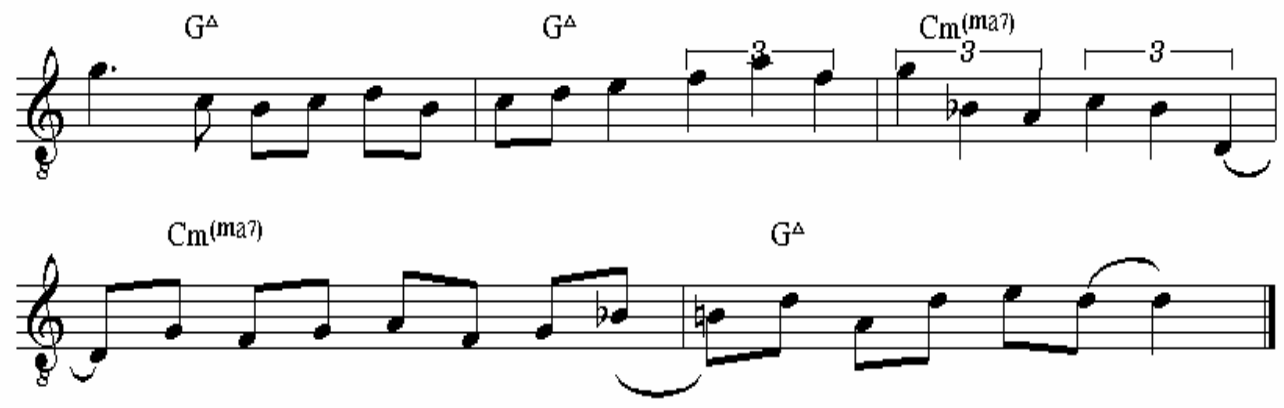

Figure 4

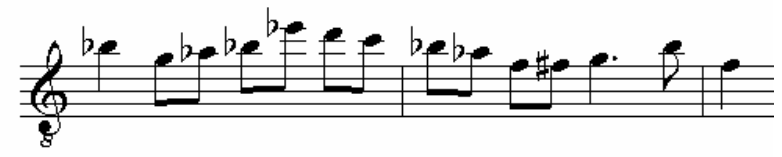

Figure 5

John noted that,

I heard myself playing that chromatic line and then heard myself change it. I remember playing that chromatic thing and thinking 'nooooo'. It often sounds a bit dry to me playing like that so I try and avoid it.

This example clearly demonstrates the ways in which preferences for particular ways of playing were used by John to direct the creation of an improvised line. Both the examples that John played are 'appropriate' ways of approaching improvisation, in that they contain features such as note phrasing, note choices, rhythm, and timbre that can be heard as consistent with musicians' expectations about 'what counts as good improvisation'. To put it another way, both Figures 4 and 5 are entirely appropriate to the harmonic setting he was playing in. What John's comments clearly show, however, is that within the range of 'appropriate possibilities' that musicians know about, he has clear stylistic preferences and that he monitors his own playing in relation to these, selecting from the array of possibilities those that are consistent with his tastes.

\section{Editing}

When listening to the second of the tunes we played that day (Autumn Leaves), John again stopped the tape and commented that,

There was a definite line there that I was inferring that I didn't want to play so I sort of played the first bit of it and then stopped and edited myself and just let it be a chromatic line on the top. 
In the course of improvising, John was aware of 'a conventional thing that he could do' which he attempted to avoid. The line which he was inferring is represented in Figure 6, while the line that he actually played is seen in Figure 7.

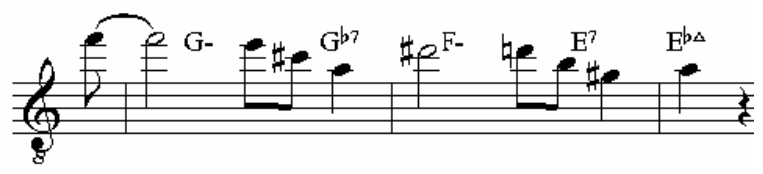

Figure 6

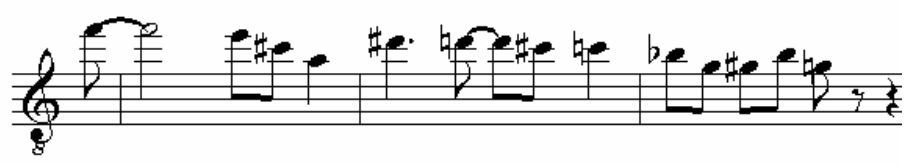

Figure 7

John commented further that,

That sort of thing is going on in your mind as you go. There are obvious things that you could play there, they are obvious cos [as in this example] the chords are moving down, you know, so you can play those chords all the way down and it would work nicely, but then I got the feeling 'no, don't do that'. I heard the line and felt that would be a thing to do and then I just thought 'no'. Those kinds of self-editing things go on all the time when you're playing I think. Little decisions.

This comment captures the extent to which the process of improvisation involves operating with a set of understandings about the intersubjectively recognisable, contextually self-evident features of performance. The structural parameters of the song being played, the palette of improvisatory possibilities that relate to that structure, the knowledge of previous (enshrined) solutions to the problems of how to improvise over certain chords, and aesthetic preferences about preferred solutions are all used to make real-time choices within improvisation. In this example John demonstrates the extent to which creating improvisation involves using shared knowledge. The fact that he can recognise an 'obvious' thing to do demonstrates the extent to which musicians share an understanding of potential solutions to problems of 'how to improvise over chord structures'. Furthermore, John's comments again show the extent to which musicians operate with preferences regarding these intersubjectively recognisable solutions, and can, for example, deliberately structure their playing in order to avoid these most obvious solutions. 


\section{Concluding remarks}

One of the central aims of this paper was to explore the ways in which 'play', in the sense of 'participating in social action', can be used as a resource for talking about those activities and, in turn, yield data for understanding them in detail. Through the data that I have presented here I illustrated how our performance enabled John to contextualise his talk in detailed ways. Our play generated data that enabled me to see how accompaniment, emotionality, personal style and editing all featured within John's improvised performance. It is clear from both this data and the other interviews in the study that the conventions and expectations that form the intersubjective understandings of 'how to improvise' are key resources that jazz musicians draw on while improvising.

The concept of 'play' has been used here to refer to the participation in the practices or activities being studied. I stated at the beginning of this paper that conventional interview settings are often not good environments for picking out the detailed aspects of social practices, as they rely heavily on the memory of participants and their abilities to articulate extremely complex features of social action within the confines of a distinctive social setting (Benson and Hughes 1983). The approach adopted in this research, which involved recording myself improvising musical performances with my research participants and using these as a referent for further discussion, enabled me to create a detailed context for conversation. As the exploration of data presented above demonstrates, John used the audio 'text' to explain what he had been doing at specific parts of the performance, and to give detailed explanations of why he had chosen the particular actions he had. It also acted as a prompt to further ideas, sparking off new areas of discussion that related to the things he was hearing. In this way then, our play became a site of interrogation which led to a detailed and contextualised account of the practices I was interested in researching.

My central empirical concern here has been with the exploration of intersubjective knowledge, specifically with the use of 'community knowledge' by musicians in the production of improvised performance. We have seen in the above discussion the ways in which the act of jazz improvisation relies on a shared understanding of the 'rules' of performance, and how musicians use the unfolding actions that comprise what I referred to as the 'musical interaction order' as a context for new ideas. Jazz improvisation then needs to be understood as a contextually bounded activity in which the rules of the game (both at a general level, and at the level of the local performance) not only frame but also constitute the sense of a performance. Improvisers are active participants in each other's perceptual fields, and they feed each other ideas, and build on each other's interjections, using the understandings that they have built up through years of playing as resources for making sense of the sounds that constitute the music they are making. When jazz musicians speak of 'play', they refer to exactly these types of practices; it was only through engaging in this play that I was able to understand in detail how jazz musicians use their knowledge.

\section{References}

Bailey, D. 1992. Improvisation: Its Nature and Practice in Music. New York: Da Capo Press. 
Becker, H. 1982. Art Worlds. Berkeley: University of California Press.

Benson, D. and J. A. Hughes. 1983. Sociological Research: Problems of Phenomena and Their Description. The Perspective of Ethnomethodology. Essex: Longman Group Ltd.

Crossley, N. 1996. Intersubjectivity: The Fabric of Social Becoming. London: Sage.

DeNora, T. 2000. Music in Everyday Life. Cambridge: Cambridge University Press.

DeVeau, S. 1991. Constructing the jazz tradition: jazz historiography. Black American Literature Forum 25(3), 525-560.

Garfinkel, H. 1967. Studies in Ethnomethodology. Cambridge: Polity.

Goffman, E. 1969. The Presentation of Self in Everyday Life. London: Allen Lane.

Hammersley, M. and P. Atkinson. 1983. Ethnography: Principles in Practice. London: Routledge.

Heritage, J. 1984. Garfinkel and Ethnomethodology. Cambridge: Polity Press.

Martin, P. 1995. Sounds and Society: Themes in the Sociology of Music. Manchester: Manchester University Press.

Martin, P. 1996. Improvisation in jazz: towards a sociological model. Manchester Sociology Occasional Papers 45.

Merleau-Ponty, M. 1962. Phenomenology of Perception. London: Routledge.

Schieffelin, B. 1990. The Give and Take of Everyday Life: Language Socialization of Kaluli Children. Cambridge: Cambridge University Press.

Theureau, J. and F. Geneviève. 2000. Analysing cooperative work in an urban traffic control room for the design of a coordination support system. In Workplace Studies: Recovering Work Practice and Informing System Design (eds) P. Luff, J. Hindmarsh and C. Heath. Cambridge: Cambridge University Press.

Townsend, P. 2000. Jazz in American Culture. Edinburgh: Edinburgh University Press.

\section{About the author}

Will Gibson has worked as a qualitative researcher on a diverse range of projects, including the assessment of professional skills, the use of online learning technologies, and the examination of musical performance. He completed a $\mathrm{PhD}$ in Sociology at the University of Manchester, entitled 'The Collaborative Process of Jazz Improvisation', and now works as a Lecturer in Social Research at the University of London, Institute of Education. He is particularly interested in interactional sociology and the empirical examination of technology and work practices. He can be contacted atw.gibson@ioe.ac.uk 